\title{
The Dual Effects of Silibinin on Human Pancreatic Cells
}

\author{
Su-Mi $L^{1 *}$, Gil-Woo $L^{2 *}$, Seon-Young $P^{1}$, Hosouk J ${ }^{1}$, \\ Eun-Ae C', Hyun-Soo K', Sung-Kyu C ${ }^{1}$, J ong-Sun \\ $\mathbf{R}^{1}$ and Chang Hwan $P^{* 1}$ \\ ${ }^{1}$ Department of Internal Medicine, Division of \\ Gastroenterology and Hepatology, Chonnam National \\ University Medical School, Gwangju, South Korea \\ ${ }^{2}$ Division of Integrative Biosciences and Biotechnology, \\ Pohang University of Science and Technology, Pohang, \\ South Korea
}

*Correspondling author: Chang-Hwan P, Department of Internal Medicine, Chonnam National University Medical School42, J aebongro, Dong-ku, Gwangju, 61469, South Korea

Received: July 06, 2021; Accepted: July 24, 2021;

Published: July 31, 2021

\section{Abstract}

Objective: Silibinin is a flavonoid with antihepatotoxic properties, and exhibits pleiotropic anticancer effects. However, the molecular mechanisms responsible for its anticancer actions in pancreatic cancer cells, and the effects on such cells and normal pancreatic cells, remain unclear. The objective of this study was to determine the effect of silibinin on human pancreatic cancer cells and normal ductal cells.

Methods: Human pancreatic cancer cells (MIA PaCa-2 and PANC-1) and normal ductal cells (hTERT-HPNE) were cultured with 0-400 $\mu \mathrm{M}$ silibinin for 48 $\mathrm{h}$. Thereafter, the proliferation, invasion, apoptosis, and signaling pathways of the pancreatic cells were evaluated.

Results: Silibinin significantly inhibited the proliferation, invasion, and spheroid formation of human pancreatic cancer cells in vitro in a dosedependent manner $(p<0.05)$. It also induced apoptosis in a dose-dependent manner. Western blot analysis showed that silibinin downregulated extracellular signaling-regulated kinase (ERK) and serine/threonine protein kinase (AKT) in human pancreatic cancer cells. It also upregulated microtubule associated protein 1 light chain $3 \beta$ (LC3B) and cleaved caspase-3 via c-Jun N-terminal kinases (JNK) signaling. On the other hand, silibinin increased the mRNA and protein levels of c-Jun, Twist-related protein 1, and Snail. It also decreased exogenous p53 levels, but increased endogenous c-Jun protein levels in human pancreatic cancer cells. However, silibinin did not affect cell viability and endogenous c-Jun levels in pancreatic normal ductal cells. It increased exogenous p53 levels, but decreased stemness-related gene expression in pancreatic normal ductal cells. Silibinin increased Ki-67 levels in pancreatic cancer cells, but decreased them in pancreatic normal ductal cells.

Conclusion: Silibinin not only exerted anticancer effects by inhibiting AKTERK and JNK signaling, but also upregulated cancer stemness-related genes in human pancreatic cancer cells. These results suggest that silibinin should be used as a therapeutic agent for human pancreatic cancer with caution.

Keywords: Silibinin; Pancreatic cancer cells; Anti-cancer drug; Pancreatic normal cells

\section{Introduction}

Pancreatic cancer is a highly malignant disease that is characterized by locally advanced, unresectable disease, or metastasis at the time of diagnosis. Despite significant advances in surgery and chemotherapy, the five-year survival rate of patients with pancreatic cancer has not significantly improved beyond $<5 \%$ [1-3]. In particular, no curative treatment options exist for patients with advanced cancer. Resistance of pancreatic cancer cells to chemotherapeutic agents is a major problem in oncology [4]. Therefore, new treatment options that can overcome the chemotherapy resistance of pancreatic cancer cells are urgently needed.

Silybum marianum or milk thistle, from which silibinin is extracted, is an annual or biannual plant of the Asteraceae family. Originally native to Southern Europe and Asia, the plant is now found throughout the world. The medicinal part of the plant is its ripe seed $[5,6]$. It has been used to treat liver diseases (cirrhosis, jaundice, and hepatitis) and gallbladder disease. It has been claimed to protect the liver against poisons [7]. Silibinin is a hepatoprotective antioxidant that can stabilize and protect the membrane lipids of hepatocytes [8]. It can inhibit peroxidase and lipoxygenase $[9,10]$. Previous studies have shown that silibinin exerts anticancer effects on colon cancer, liver cancer, and breast cancer [11-14]. The role of silibinin in pancreatic cancer cells is as follows. Firstly, silibinin induces apoptosis of pancreatic cancer cells through a multi-signal pathway. Silibinin induces apoptosis by activating c-Jun N-terminal kinases /Stress-activated protein kinases (JNK/SAPK) signaling in SW1990, a human pancreatic cancer cell line $[15,16]$. Furthermore, silibinin induces apoptosis by downregulating the Glucagon-Like Peptide-1 Receptor and Protein Kinase A (GLP-1R/PKA) signal pathway in cells of INS-1, a rat insulinoma cell line, with amylin [17]. Secondly, silibinin reduces the tumor volume and inhibits weight loss in nude mice with BxPC-3 and PANC-1(kind of pancreatic ductal adenocarcinoma cell lines) tumor xenografts [18].

The molecular mechanisms involved in the anticancer action of silibinin are complex. Moreover, the targets or molecular mechanisms in human pancreatic cancer cells are the least studied compared with those in other cancers. 
Cancer Stem Cells (CSCs) are cells that possess the ability to selfrenew and differentiate into various types of mature cells. Such cells are rare in cancer. However, they play an important role in cancer homeostasis, metastasis, resistance to therapy, and subsequent tumor recurrence $[19,20]$. Pancreatic CSCs are associated with poor prognosis, tumor recurrence and metastasis, and epithelial mesenchymal transition [21].

c-Jun protein is an oncogenic transcription factor that is encoded by the Jun gene in humans, and undergoes a combination Activator Protein 1 (AP-1) early response transcription with c-Fos [22]. It is involved in AKT-ERK and JNK/SAPK signaling [23]. c-Jun is an important signal for cell divisions. The G1 phase of the cell cycle arrests when c-Jun is deficient in cells. This implies that c-Jun regulates cell cycle progression and apoptosis [24]. c-Jun is required for tumor development stages, such as cell proliferation, angiogenesis, and metastasis $[25,26]$.

Twist-related protein 1 (TWIST1) is a transcription factor encoded by the TWIST1 gene in humans $[27,28]$. TWIST1 acts as an oncogene in several cancers. It cooperates with N-Myc, and plays an essential role in cancer metastasis, angiogenesis, and epithelial mesenchymal transition [29-32].

Snail is zinc-finger protein that is encoded by the Snail gene in humans. It represses E-cadherin for the promotion of epithelial mesenchymal transition during embryonic development [33]. Snail causes the recurrence of human breast cancer by repressing E-cadherin and upregulating epithelial mesenchymal transition [34].

p53 is a known tumor suppressor gene in various organisms. Mutant p53 is associated with the drug-resistant property of pancreatic cancer [35].

Prior studies have only shown the positive effects of silibinin on human pancreatic cancer cells, and there are no data on the effect of silibinin on human normal pancreatic cells.

The objective of this study was to investigate the molecular mechanism of silibinin and the responses of human pancreatic cells to silibinin treatment.

\section{Materials and Methods}

\section{Cell lines and culture}

MIA PaCa-2 and PANC-1 are p53-mutated pancreatic cancer cell lines that are derived from human pancreatic carcinoma [18]. hTERT-HPNE is a human pancreatic normal ductal cell line. These pancreatic cancer cell lines were cultured in Dulbecco's Modified Eagle's medium (DMEM) (GIBCO Invitrogen Inc., USA) containing $4.5 \mathrm{mg} / \mathrm{L}$ glucose, $100 \mathrm{mg} / \mathrm{L}$ streptomycin, and $2 \mathrm{mM} \mathrm{L}$-glutamine supplemented with $10 \%$ Fetal Bovine Serum (FBS) (GIBCO Invitrogen Inc.). hTERT-HPNE (ATCC ${ }^{\circ}$ CRL-4023 $^{\text {mo }}$, USA) cells were grown in DMEM containing $1.0 \mathrm{mg} / \mathrm{L}$ glucose (low glucose), $100 \mathrm{mg} / \mathrm{L}$ streptomycin, and $2 \mathrm{mM} \mathrm{L}$-glutamine supplemented with $10 \% \mathrm{FBS}$ and $10 \mathrm{ng} / \mathrm{mL}$ human epidermal growth factor (hEGF) (MERCK, USA). The cells were sub-cultured following enzymatic digestion using trypsin-EDTA solution (GIBCO Invitrogen Inc.), and were maintained under a humidified atmosphere at $37^{\circ} \mathrm{C}$ in a $5 \% \mathrm{CO}_{2}$ incubator (Sanyo, Japan).

\section{Flow cytometry analysis}

Apoptosis assay: MIA PaCa-2, PANC-1, and hTERT-HPNE cells were seeded in six-well cell culture plates at a density of $1 \times 10^{5}$ cells/well. After overnight culture, the cells were treated with various concentrations $(0-400 \mu \mathrm{M})$ of silibinin for $24 \mathrm{~h}$; then, the cells were harvested using $0.005 \mathrm{M}$ trypsin-EDTA, and washed thrice with PBS. The cells were then stained with Annexin V Apoptosis Detection Kit I (51-66211E; BD Pharmingen ${ }^{\mathrm{rw}}$, USA). The stained cells were acquired and analyzed using Canto II (BD Pharmingen ${ }^{\mathrm{ms}}$ ) and FlowJo software (Tree Star Inc., USA).

Ki-67 analysis: Cells were stained with Ghost dye (BV510; \#59863, CST, USA) and washed thrice with PBS. For intracellular staining, cells were stained using a FoxP3/transcription factor staining buffer set (00-5523; eBioscience, USA) and APC-conjugated anti-human Ki-67 (350514; Biolegend, USA).

\section{Western blot analysis}

Proteins were extracted from silibinin $(200 \mu \mathrm{M} / \mathrm{mL})$-treated pancreatic cells (the cells were cultured to $70 \%$ confluence in 60 $\mathrm{mm}$ dishes) using a radioimmunoprecipitation assay buffer (Sigma R0278, Sigma-Aldrich Co. LLC, USA) containing a protease inhibitor (\#p8340, Sigma-Aldrich) and a phosphatase inhibitor (\#p2850, Sigma-Aldrich). The proteins were separated using 10\% SDS-polyacrylamide gel electrophoresis, and blotted onto PVDF membranes (Millipore Corporation, Billerica, MA, USA). These membranes were blocked with $5 \%(\mathrm{w} / \mathrm{v})$ skim milk in TBS-T $(20$ $\mathrm{mM}$ Tris, $\mathrm{pH} 7.6,136 \mathrm{mM} \mathrm{NaCl}$ containing $0.1 \%(\mathrm{v} / \mathrm{v})$ Tween-20) at $25^{\circ} \mathrm{C}$ for $1 \mathrm{~h}$. After washing thrice with TBS-T, the membranes were incubated overnight with diluted primary antibodies (all antibodies were from Cell Signaling Technology Inc., USA; antibody:TBS-T = $1: 1,000)$ at $4^{\circ} \mathrm{C}$. After washing thrice with TBS-T for $10 \mathrm{~min}$ each, the membranes were incubated with either anti-rabbit or anti-mouse horseradish peroxidase-conjugated secondary antibodies. ECL SuperSignal chemiluminescent substrate (Millipore Corporation, Billerica, MA, USA) was used to develop the membrane. Protein bands were then visualized using a LAS 3000 Imaging System (FujiFilm, R\&D Systems, Minneapolis, MN, USA).

\section{Spheroid formation assay}

Cells were seeded in six-well plates at a density of $1 \times 10^{3}$ cells/well, and cultured in F-12 DMEM (GIBCO Invitrogen Inc.) containing 10 $\mathrm{ng} / \mathrm{mL}$ human recombinant basic Fibroblast Growth Factor (bFGF) (R\&D Systems) and $10 \mathrm{ng} / \mathrm{mL}$ hEGF (R\&D Systems) with $1 \times \mathrm{N}_{2}$ supplement (GIBCO Invitrogen Inc.). The cells were incubated at $37^{\circ} \mathrm{C}$ under a humidified atmosphere containing $5 \% \mathrm{CO}_{2}$. Spheroids were confirmed after 14 days.

\section{Invasion assay}

Cell invasion was carried out overnight using a transwell filter chamber $(8.0-\mu \mathrm{m}$ pores) coated with $1 \%$ gelatin/DMEM, followed by drying at RT. Pancreatic cancer cells were harvested, washed once with the growth culture medium, and seeded on the upper chamber at $2 \times 10^{5}$ cells in $120 \mu \mathrm{L} 0.2 \%$ BSA medium. Then, $400 \mu \mathrm{L}$ $0.2 \%$ BSA medium containing $20 \mu \mathrm{g} / \mathrm{mL}$ human plasma fibronectin (Calbiochem, La Jolla, CA, USA) was loaded into the lower chamber. The transwell apparatus was incubated at $37^{\circ} \mathrm{C}$ for $24 \mathrm{~h}$. Cells that invaded the bottom surface of the upper chamber were fixed with 
70\% ethanol and stained with Diff-Quik solution (Sysmex, Kobe, Japan), according to the manufacturer's protocol. Non-invasive cells on the top surface were wiped off with cotton balls and stained. Cells on the bottom surface were counted in five selected fields (each 0.5 $\mathrm{mm}^{2}$ ), using a hematocytometer under a light microscope at $\times 400$ magnification. The results were expressed as means \pm SE of the number of cells per field from three individual experiments.

\section{RNA isolation}

Total RNA was extracted using TRIzol (Takara, Japan). Briefly, $1 \mathrm{~mL}$ TRIzol solution was added into each well, and the suspensions were transferred to $1.5 \mathrm{~mL}$ tubes. After adding $200 \mu \mathrm{L}$ chloroform (Sigma-Aldrich) and vortex mixing for $15 \mathrm{~s}$, the mixtures were centrifuged at $4^{\circ} \mathrm{C}$ and $6,000 \times \mathrm{g}$ (grams) for $20 \mathrm{~min}$. The supernatants were then collected, mixed with equal amounts of isopropyl alcohol (MERCK), and centrifuged at $4^{\circ} \mathrm{C}$ and $6,000 \times \mathrm{g}$ for $20 \mathrm{~min}$. The pellets were washed with $1 \mathrm{~mL} 70 \%$ ethyl alcohol (MERCK) and centrifuged at $4^{\circ} \mathrm{C}$ and $6,000 \times \mathrm{g}$ for $5 \mathrm{~min}$. After removing the remaining ethyl alcohol, the RNA pellets were air-dried at RT. They were then resuspended in $50 \mu \mathrm{L}$ diethyl pyrocarbonate water.

\section{Real-time polymerase chain reaction (PCR)}

Total RNAs were converted to cDNAs using a reverse transcription system (Promega Corporation, WI 53711-5399, USA). Real-time PCR was performed with an Applied Biosystems StepOnePlus ${ }^{\text {ma }}$ (Thermo Fisher Scientific, MA, USA) Real-Time PCR system, according to the manufacturer's protocol. Glyceraldehyde 3-phosphate dehydrogenase (GAPDH: HS02786624-g1) was used as a control, and the del/del threshold cycles ( $2^{-\Delta \Delta C T} \mathrm{CTs}$ ) values were calculated for stem markers (TWIST1: HS 01675818_s1, c-Jun: HS01103582_s1, and Snail: HS00195591_m1). The probes used were Thermo Fisher Taqman Assay probes (Thermo Fisher Scientific).

\section{Wild-type p53 gene transfection}

Cells were seeded in six-well plates and incubated at $37^{\circ} \mathrm{C}$ overnight. The cells were then transfected with pcDNA3/wild-type p53 (plasmid \#69003, Addgene, MA 02472, USA) expression plasmid vector, using FuGENE 6 (Cat.\#E2693, Promega Corporation) reagent, according to the manufacturer's protocol.

\section{Statistical analysis}

The two-tailed paired t-test was used to assess statistical significance appropriately. The statistical significance of differences between data sets was determined using the paired t-test and oneway ANOVA test. All the reported $p$ values are two-sided; $\mathrm{p} \leq 0.05$ was considered statistically significant. The Statistical Package for the IBM SPSS Statistics 23 software (SPSS Statistics Inc., Chicago, IL, USA) was used for all statistical analyses.

\section{Results}

\section{Silibinin induces apoptosis of pancreatic cancer cell lines}

Cells were stained with AnnexinV-FITC and Propidium Iodide (PI), and analyzed using flow cytometry. The binding of fluorescently labeled Annexin $\mathrm{V}$ to externalized phosphatidylserine was also

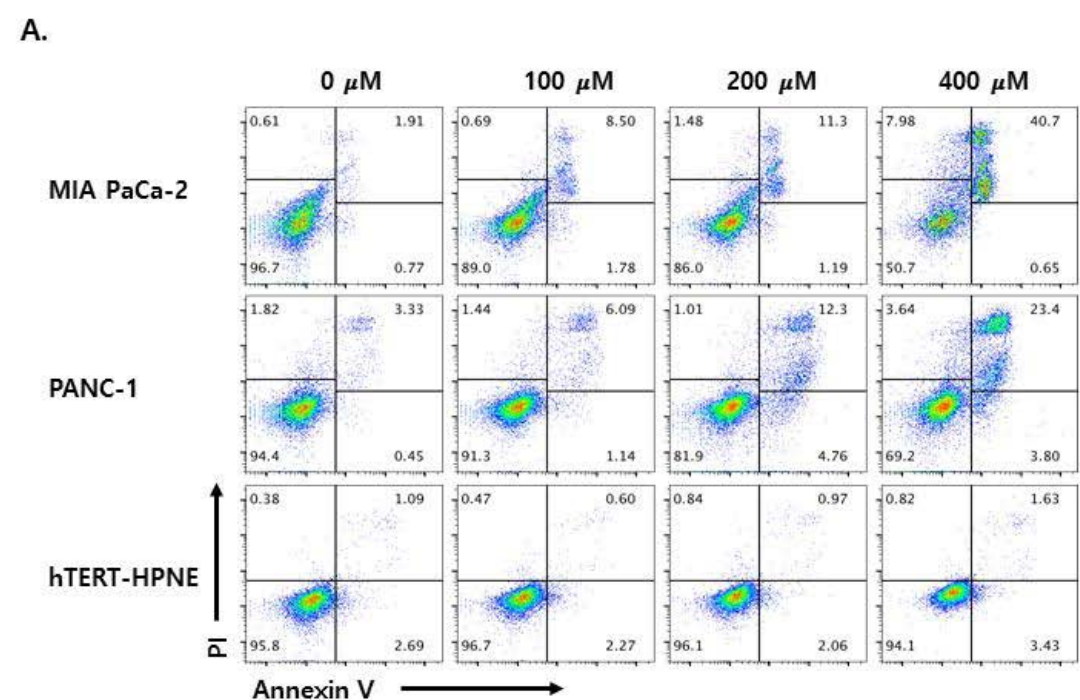

B.
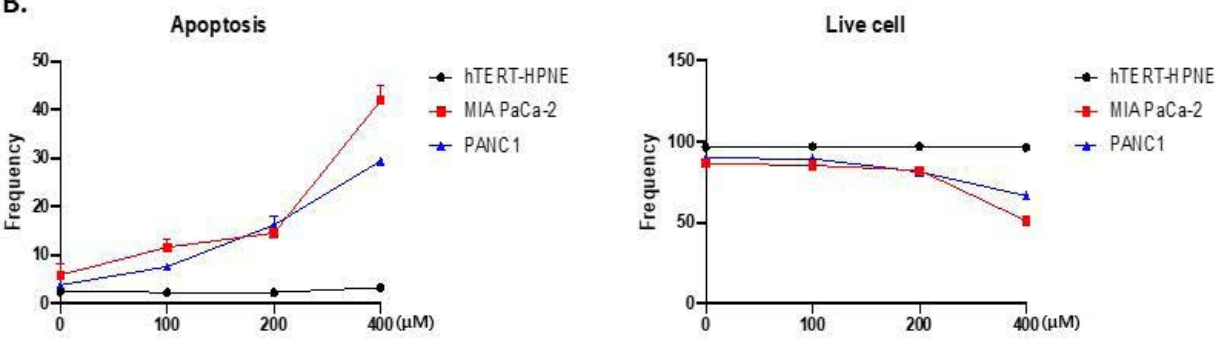

Figure 1: (A) Apoptosis assay of MIA PaCa-2, PANC-1 (human pancreatic adenocarcinoma ductal cell lines), and hTERT-HPNE (human pancreatic normal ductal cell line) after silibinin treatment. Data are representative of three independent experiments. (B) Silibinin induces apoptotic cell death in both MIA PaCa-2 and PANC-1 cells in a dose-dependent manner, but does not affect hTERT-HPNE cells $(p<0.0001)$. 

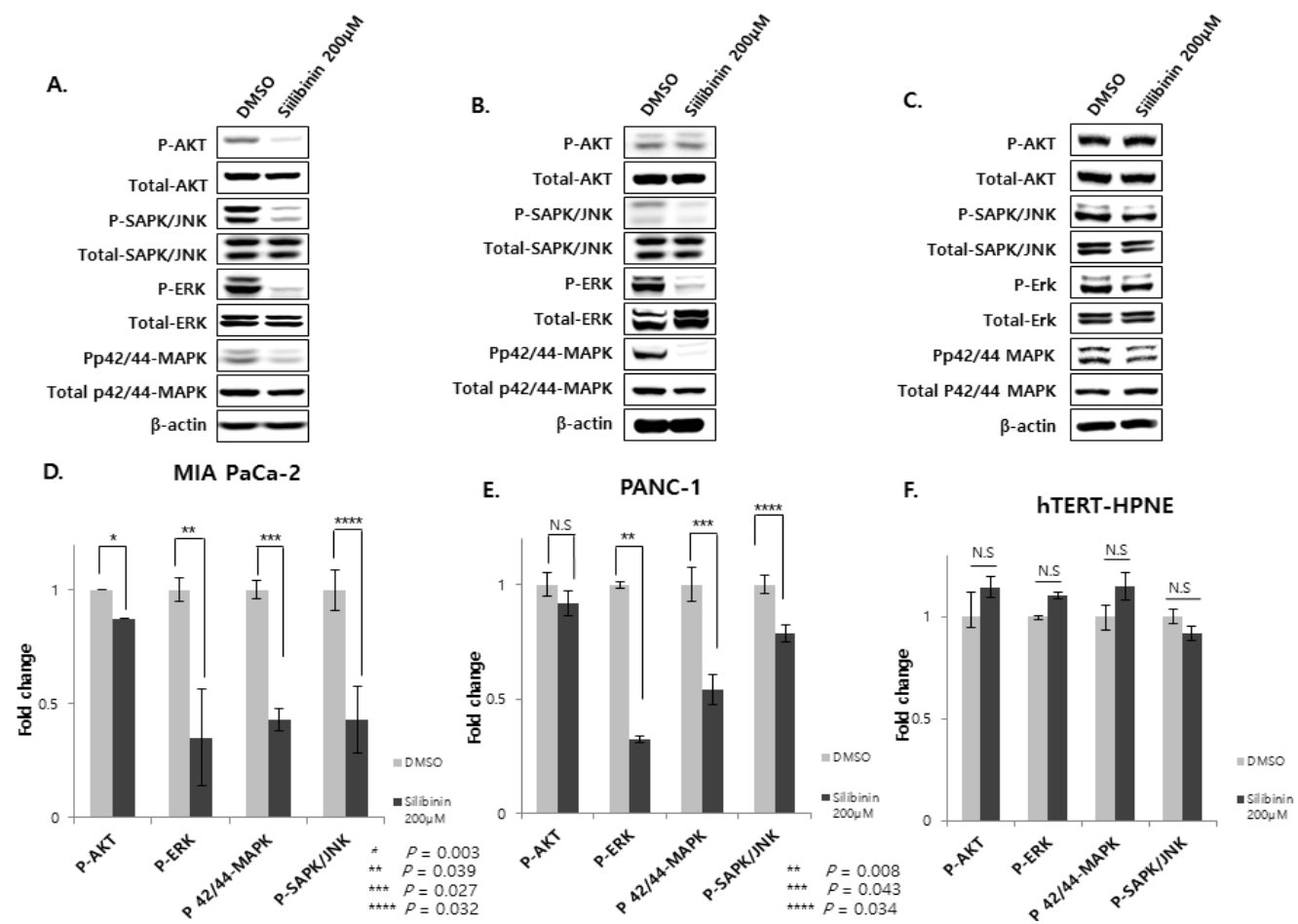

Figure 2: Silibinin decreases the expression of phosphorylated AKT, ERK 1/2, JNK, and p42/44 MAPK in pancreatic cancer cells (MIA PaCa-2 and PANC-1). However, silibinin increases the expression of phosphorylated AKT $(p<0.01)$, ERK $1 / 2(p<0.05)$, SAPK/JNK $(p<0.05)$, and $p 42 / 44$ MAPK $(p<0.05)$ in normal pancreatic ductal cells (hTERT-HPNE). A and D: MIA PaCa-2, B and E: PANC-1, and C and F: hTERT-HPNE cells are incubated with or without silibinin (200 $\mu \mathrm{M})$ for $24 \mathrm{~h}(\mathrm{p}<0.05)$.

determined using flow cytometric analysis to quantify early apoptotic cells. PI uptake was measured to assess cells in the late stage of apoptosis, or cells that sustained direct plasma membrane damage. Figure 1 shows the flow cytometric plots obtained with AnnexinVFITC PI assay after $24 \mathrm{~h}$ exposure to different concentrations (0-400 $\mu \mathrm{M})$ of silibinin. After cell exposure to silibinin, the number of early and late apoptotic or directly damaged MIA PaCa-2 and PANC-1 cells significantly $(\mathrm{p}<0.001)$ increased. However, silibinin did not affect the cell viability of hTERT-HPNE cells $(\mathrm{p}<0.001)$ (Figure 1$)$.

\section{Silibinin decreases phosphorylation of ERK-SAPK/JNK} signaling proteins in human pancreatic cancer cell lines

Silibinin can modulate the phosphorylation of mitogen-activated protein kinase (MAPK) cascade signaling proteins in human pancreatic cancer cells [9]. The effect of silibinin on the MAPK signal pathway, which is essential for cell survival and growth during development and carcinogenesis, was examined. Silibinin treatment significantly decreased the expression levels of phosphorylated ERK $1 / 2$ and phosphorylated p42/44 MAPK (Figure 2A,2B,2D and $2 \mathrm{E}$, respectively). As crosstalk between signal transduction pathways is common, we examined whether silibinin prevented the phosphorylation of p-ERK or SAPK/JNK in human pancreatic cancer cells. Silibinin treatment decreased the phosphorylation levels of AKT and SAPK/JNK. However, it did not alter the levels of total ERK 1/2, SAPK/JNK, p42/44-MAPK, and AKT (Figure 2A,2B,2D and 2E, respectively). Furthermore, silibinin did not affect phosphorylation, or the total levels of AKT and SAPK/JNK in hTERT-HPNE cells (Figure 2C and 2F).

\section{Silibinin increases autophagy and apoptosis signaling in pancreatic cancer cell lines}

Silibinin-induced apoptosis is associated with the modulation of apoptotic regulatory proteins in human pancreatic cancer cells [1315]. The expression levels of cleaved caspase- 3 and LC3B significantly increased in MIA PaCa-2 and PANC-1 cells following treatment with $200 \mu \mathrm{M}$ silibinin (Figure 3A,3B,3D and 3E, respectively). However, silibinin did not affect the levels of cleaved caspase-3 and LC3B in hTERT-HPNE cells (Figure 3C and 3F).

\section{Silibinin decreases spheroid formation in pancreatic cancer cell lines}

Cancer cells can be cultured in suspension to form spheres in a serum-free replacement medium. To test whether human pancreatic cancer cell lines could form spheres, MIA PaCa- 2 and PANC-1 cells were cultured in a suspension culture system. Silibinin decreased the number of colonies after 14 days of incubation. We also observed a smaller number of colonies in silibinin-treated cultures relative to that in the control, for each cell line $(\mathrm{p}<0.05)$. On average, silibinin exposure decreased the colony size of each cell line (Figure 4B).

\section{Silibinin decreases invasion and migration of pancreatic cancer cell lines}

To determine whether silibinin influenced the biological activity of the human pancreatic cancer cells used, we performed an invasion assay. After measuring six random squares of a $0.5 \times 0.5 \mathrm{~mm}$ microscope field, we found that the numbers of invading MIA PaCa-2 cells after treatment with 100 and $200 \mu \mathrm{M} / \mathrm{mL}$ silibinin were $239 \pm 3.5$ and $240 \pm 15.1$, respectively, whereas that for the negative control was 
A.

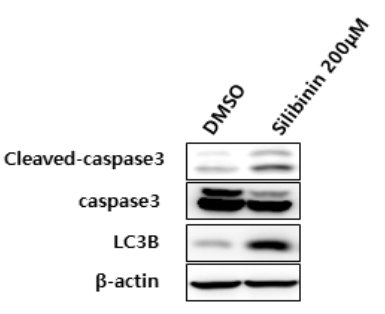

MIA PaCa-2

D.

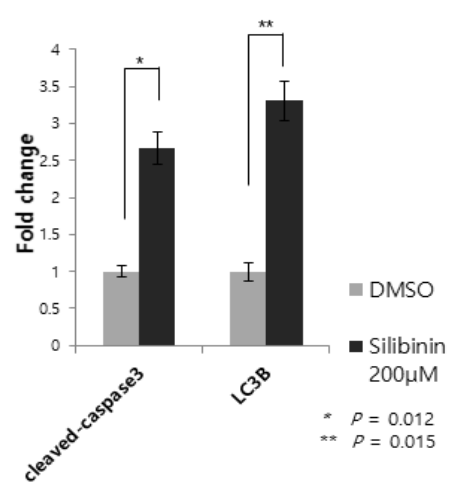

B.

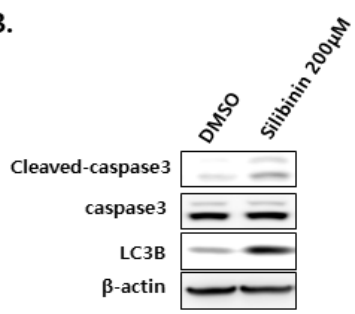

PANC-1

E.

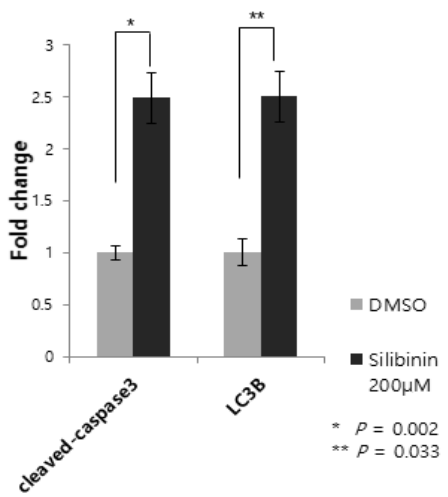

c.

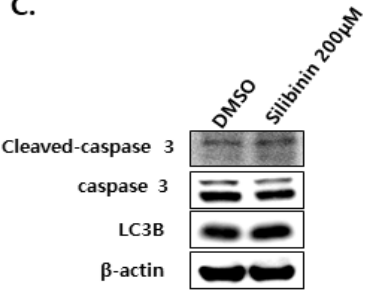

hTERT-HPNE

F.

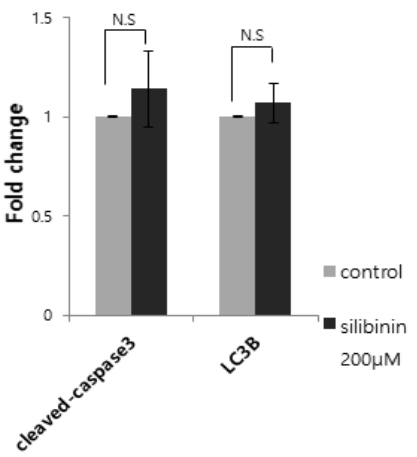

Figure 3: Effect of silibinin on apoptosis-related protein expression. Increases in the expression of cleaved caspase-3 and LC3B are detected in pancreatic cancer cells A and D: MIA PaCa-2 and B and E: PANC-1, and C and F: hTERT-HPNE cells following treatment with silibinin $(200 \mu M)$ for $24 \mathrm{~h}(p<0.05)$.

\section{A. Migration}

o h

$48 \mathrm{~h}$

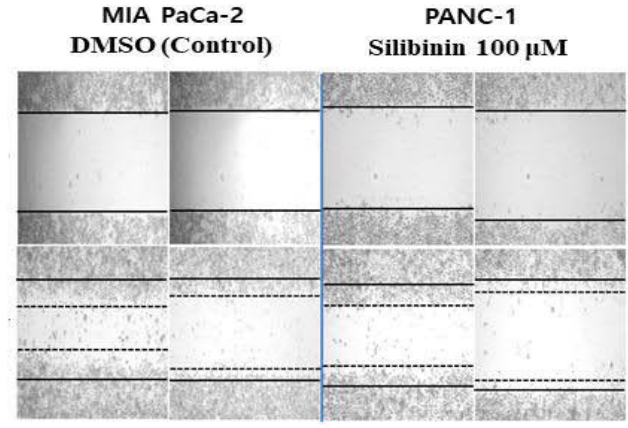

\section{Invasion}

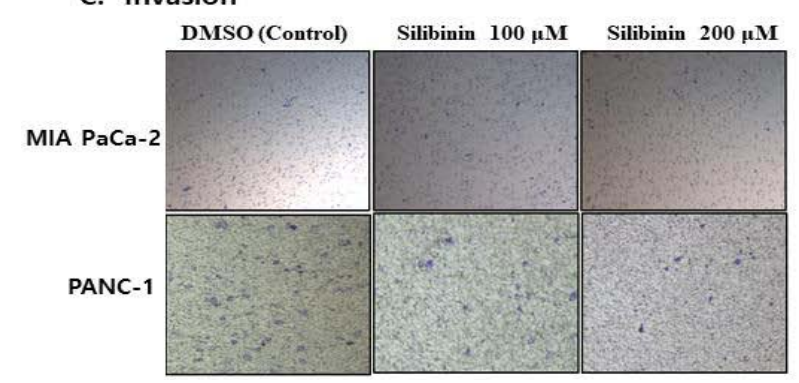

\section{B. Spheroid formation}
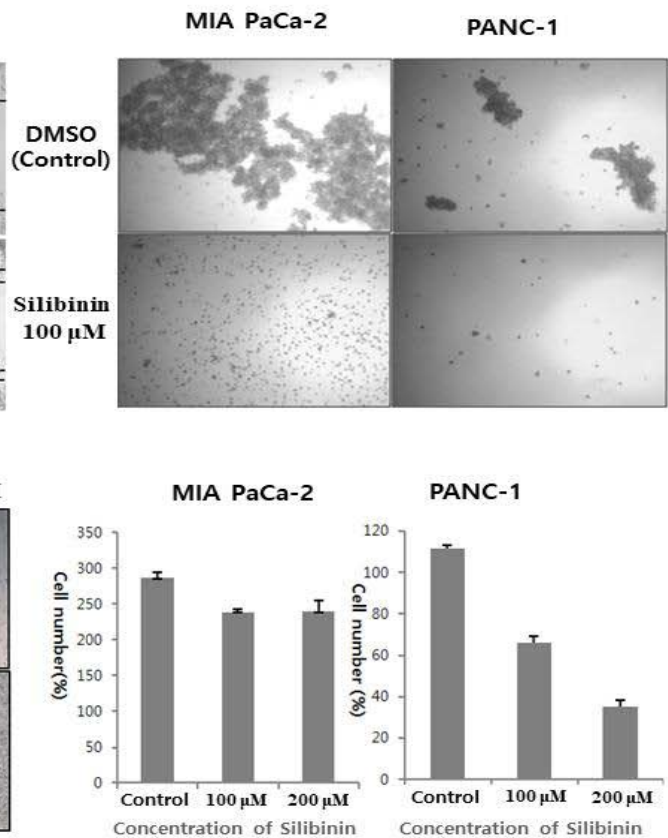

Figure 4: Silibinin decreases migration, spheroid formation, and invasion. A: Silibinin decreases migration in MIA PaCa-2 and PANC-1 cells, compared to that in the negative control. B: Silibinin decreases spheroid formation in MIA PaCa-2 and PANC-1 cells. Silibinin decreases the number of colonies after 14 days of incubation $(p<0.05)$. On average, silibinin exposure decreases the colony size in each cell line. C: Effects of silibinin on cell invasion. The numbers of invading MIA PaCa-2 cells after treatment with 100 and $200 \mu \mathrm{M}$ silibinin are $239 \pm 3.5$ and $240 \pm 15.1$, respectively, whereas that of the negative control are $286 \pm 7.3$, as measured for six random squares of a $0.5 \times 0.5 \mathrm{~mm}$ microscope field $(\mathrm{p}=0.007$ ). The numbers of invading PANC- 1 cells treated with 100 and $200 \mu \mathrm{M}$ silibinin are $66 \pm 4.24$ and $35 \pm 4.24$, respectively, whereas that of the negative control are $112 \pm 2.12$, as measured for six random squares of a $0.5 \times 0.5 \mathrm{~mm}$ microscope field $(p=0.001)$. 


\section{A. MIA PaCa-2}

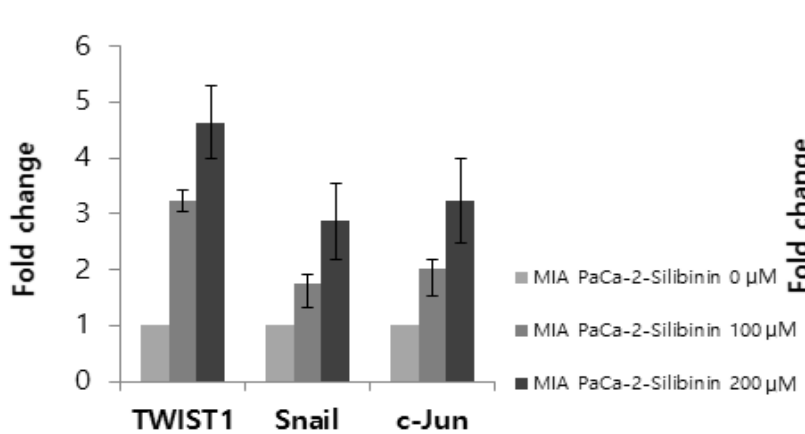

B. PANC-1

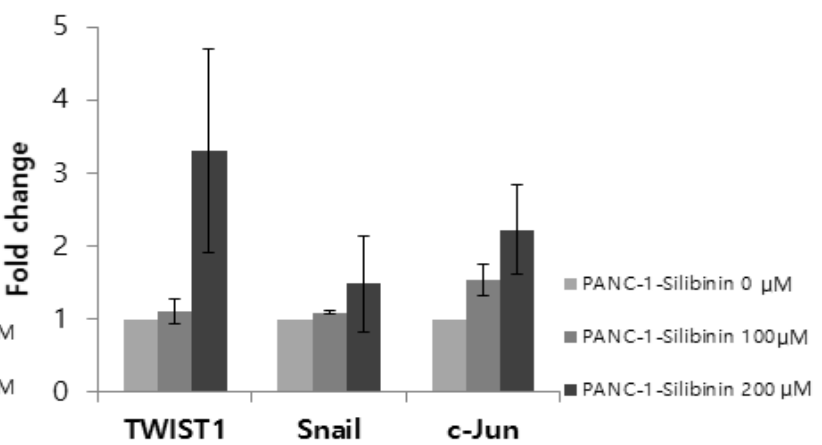

D. Other cell lines

\section{C. hTERT-HPNE}

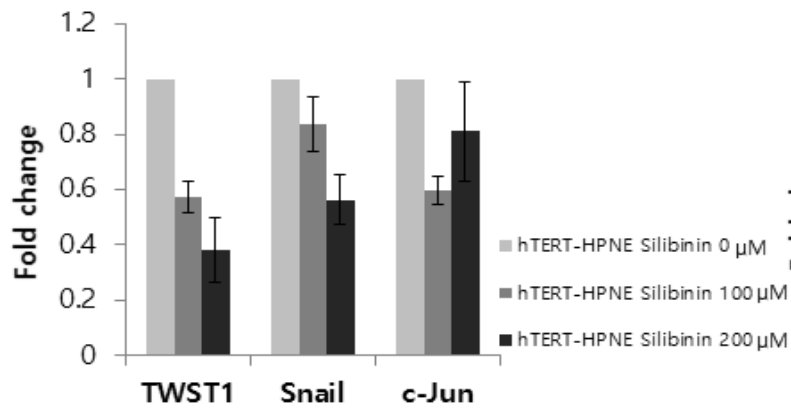

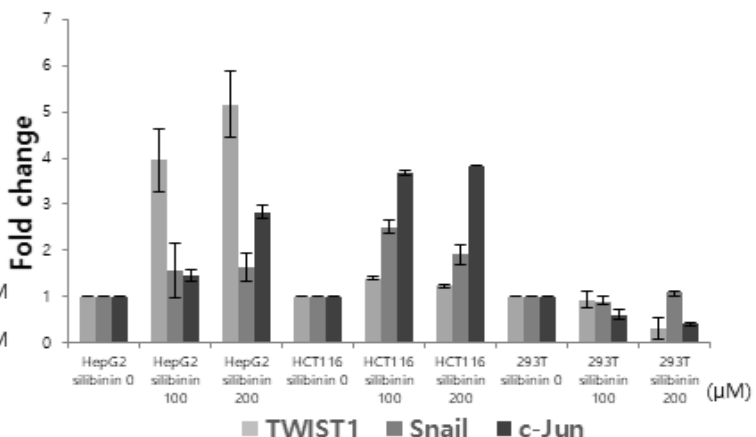

Figure 5: Expression levels of TWIST1, Snail, and c-Jun mRNA in pancreatic cancer cells: A: MIA PaCa-2, B: PANC-1, C: human pancreatic normal ductal cell line (hTERT-HPNE), and D: liver cancer cell line (HepG2), colon cancer cell line (HCT116), and normal kidney cell line (293T). The results show that TWIST1, Snail, and c-Jun mRNA expression levels are significantly higher in silibinin-treated cancer cells than in negative control cells. However, they are lower in silibinin-treated normal cells than in negative control cells $(p<0.05)$.

$286 \pm 7.3$ ( $\mathrm{p}=0.007$ ) (Figure 4C). The numbers of invading PANC-1 cells after treatment with 100 and $200 \mu \mathrm{M} / \mathrm{mL}$ silibinin were $66 \pm 4.24$ and $35 \pm 4.24$, respectively, whereas that for the negative control was $112 \pm 2.12(\mathrm{p}=0.001)$ (Figure 4C). Furthermore, silibinin treatment of MIA PaCa-2 and PANC-1 cells decreased migration, compared to that in negative control cells (Figure 4A).

\section{Silibinin increases expression of stemness-related signal pathway in pancreatic cancer cell lines}

Silibinin increased the expression levels of TWIST1, Snail, and c-Jun mRNAs in pancreatic cancer cells, compared to those in the control (Figure 5A and 5B) $(\mathrm{p}<0.05)$. However, it decreased the expression levels of TWIST1, Snail, and c-Jun in pancreatic normal ductal cells (hTERT-HPNE) (Figure 5C), compared with those in the control $(\mathrm{p}<0.05)$. The TWIST1, Snail, and $\mathrm{c}$-Jun mRNA expression levels were significantly higher in silibinin-treated cancer cells than in the negative control cells $(\mathrm{p}<0.05)$ (Figure 5D). However, the TWIST1, Snail, and c-Jun mRNA expression levels in silibinintreated normal cells were lower than those in the negative control cells $(\mathrm{p}<0.05)$ (Figure 5D).

Silibinin decreases wild-type p53 protein levels and increases c-JUN protein levels in pancreatic cancer cell lines

Silibinin decreased the $\mathrm{p} 53$ protein levels in overexpressed wild- type p53 protein pancreatic cancer cell lines (Figure 6A and 6B), however, increased those in overexpressed wild-type p53 protein pancreatic normal ductal cells (hTERT-HPNE) (Figure 6C). In addition, silibinin increased c-Jun protein levels in pancreatic cancer cell lines (Figure 6A and 6B), but decreased those in pancreatic normal ductal cells (hTERT-HPNE) (Figure 6C).

\section{Silibinin increases expression of $\mathrm{Ki}-67$ in pancreatic adenocarcinoma cell lines}

$\mathrm{Ki}-67$ is a protein encoded by the MKI67 gene, and is used as a marker of proliferation. It is overexpressed in the G1, S, G2, and $\mathrm{M}$ phases of cell cycles, but is not expressed in the G0 phase [36]. Silibinin increased the expression of $\mathrm{Ki}-67$ by $16.7 \%$ and $23.1 \%$ in the human pancreatic adenocarcinoma cell lines, MIA PaCa-2 and PANC-1, respectively. On the other hand, silibinin decreased the expression of Ki-67 by $7.3 \%$ in the pancreatic normal ductal cell line, hTERT-HPNE ( $\mathrm{p}=0.0001)$ (Figure 7A and 7B).

\section{Discussion and Conclusions}

The present study demonstrated the following findings: 1) silibinin does not affect cell viability in pancreatic normal ductal cells, but reduces cell viability, migration, invasion, and spheroid formation by downregulating AKT-ERK signaling in pancreatic adenocarcinoma cell lines; 2) silibinin decreases stemness-related signals, including the 
A. MIA PaCa-2

B. PANC-1

\section{C. hTERT-HPNE}

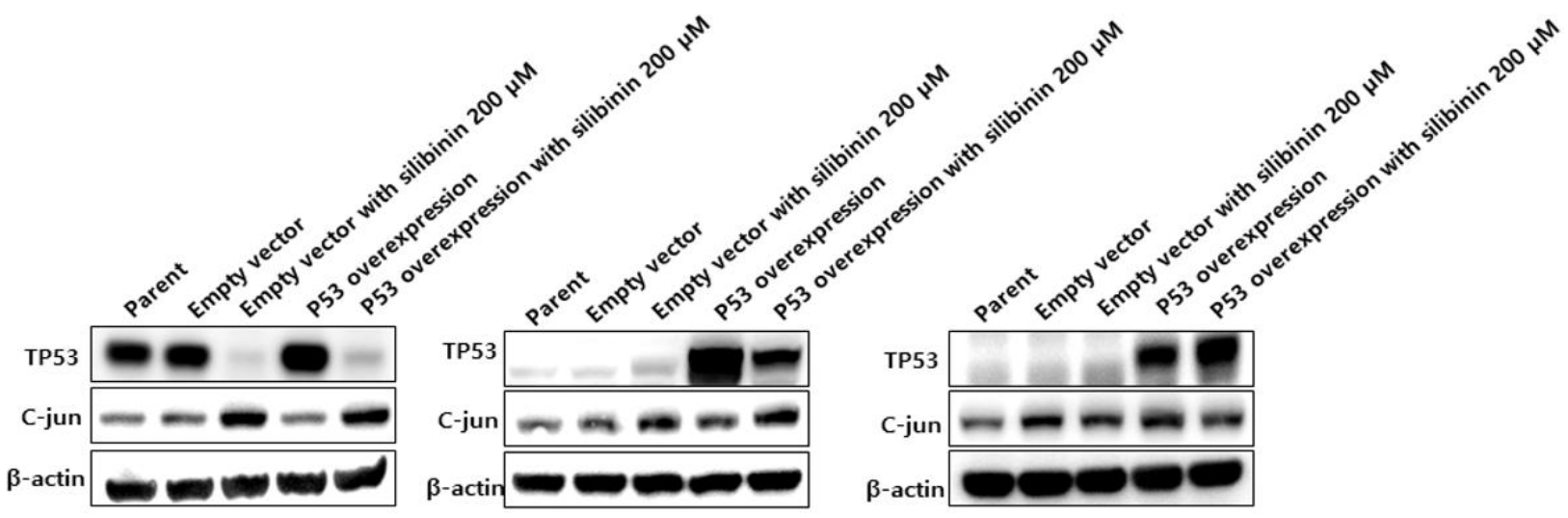

Figure 6: Silibinin reduces the exogenous wild-type p53 expression in A: MIA PaCa-2 and B: PANC-1 cells, and increases endogenous C-Jun expression. However, silibinin does not affect p53 expression and c-Jun levels in C: hTERT-HPNE cells. The expression levels are determined using western blotting.

A.

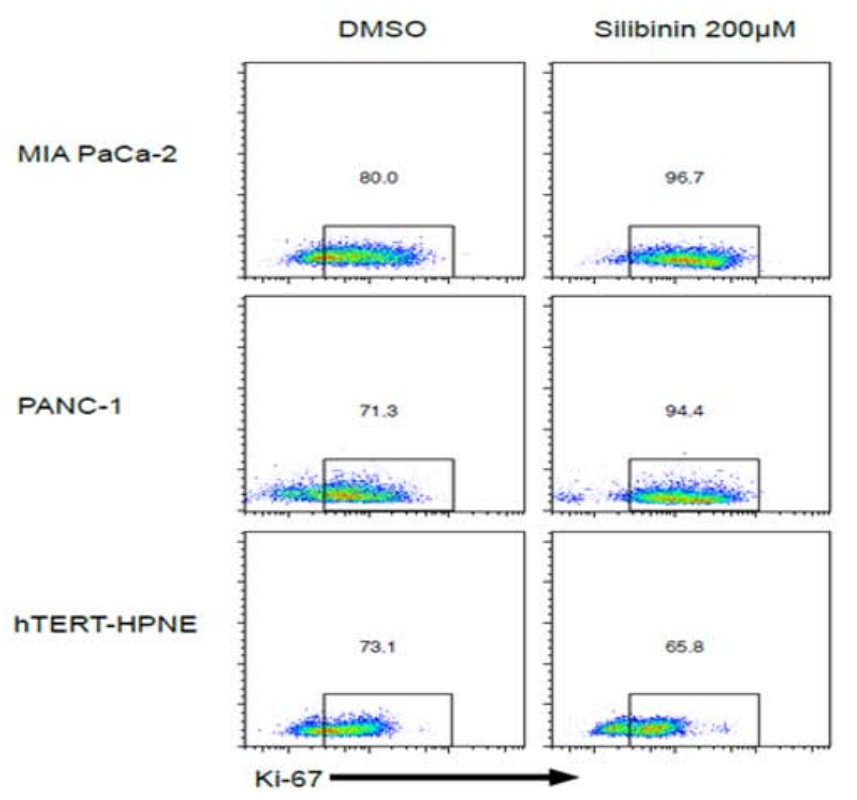

B.

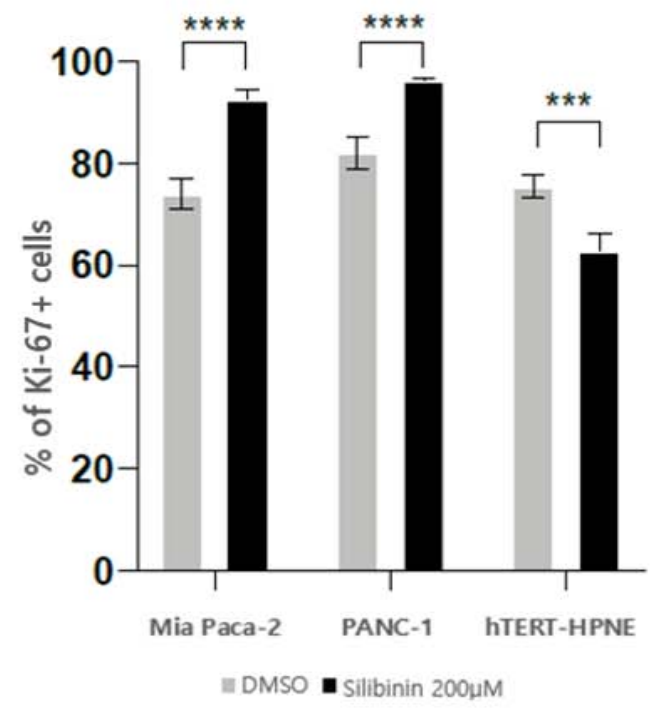

Figure 7: A and B: Proliferation analysis of cells surviving silibinin treatment. Ki-67 staining shows extensive proliferation in MIA PaCa-2 and PANC-1 cells; conversely, hTERT-HPNE cells shows a slight decrease in proliferation after silibinin treatment, followed by a one-day resting period $(p<0.0001)$.

expression of c-Jun, TWIST1, and Snail, in pancreatic normal ductal cells, but increases those in pancreatic adenocarcinoma cell lines; 3) although silibinin increases wild-type p53 levels in pancreatic normal ductal cells, silibinin reduces those in pancreatic adenocarcinoma cell lines.

Many studies have shown the tumor suppressive effects of silibinin in human cancer cells [36-38]; however, only a few studies [13,37-39] have been undertaken to elucidate silibinin-induced apoptosis in human pancreatic cancer cells.
In addition, a limitation of these previous studies is that they focused less on the signal pathway of cell death in pancreatic cancer than that in other cancers, and only the positive effects of silibinin on human pancreatic cancer cells were reported. Furthermore, no studies have been conducted on the effects of silibinin on human pancreatic normal ductal cells. Our study has shown the effect of silibinin on pancreatic cancer cell lines as well as pancreatic normal ductal cell lines. The results of our study show that the effect of silibinin is broader than that indicated by other studies; it is a potent anticancer agent, but also has the potential to cause cancer recurrence. A 
recent study suggested that silibinin could induce cell death possibly via a bcl-2-sensitive apoptotic pathway in a human pancreatic adenocarcinoma cell line (SW1990) [13]. In the present study as well, $0-400 \mu \mathrm{M} / \mathrm{mL}$ silibinin induced the apoptotic cell death of pancreatic adenocarcinoma cell lines (MIA PaCa-2 and PANC-1), based on flow cytometer analysis (Figure 1). Western blot analysis showed that silibinin downregulated the levels of AKT-ERK and SAPK/JNK in human pancreatic adenocarcinoma cells (Figure 2). ERK 1/2-SAPK/ JNK signaling is known to regulate cellular activities, including gene expression, mitosis, movement, metabolism, and programmed death [40]. Therefore, the results of the present study demonstrate that silibinin causes cell death through the p-AKT and p-SAPK/JN-ERK pathway (Figure 2). The present study has also demonstrated the additional anti-cancer effects of silibinin; it reduced cell migration, invasion, and spheroid formation by downregulating $\mathrm{p}-\mathrm{AKT}$ and p-SAPK/JNK-ERK signaling in pancreatic adenocarcinoma cell lines. However, silibinin did not downregulate p-AKT and p-SAPK/ JNK-ERK signaling in hTERT-HPNE cells (Figure 4). Our data show that cell death was induced by a decrease in c-Jun-related AKT-ERK and JNK/SAPK signaling, but this mechanism does not explain the increase in c-Jun levels. This study did not reveal the mechanism for the increase in c-Jun levels. However, we speculate that the increase in c-Jun levels involves a molecular mechanism other than AKT-ERK and JNK/SAPK signaling, because this mechanism is complex [41]. A previous study has shown that CSCs can self-renew and differentiate into mature cells [42]. They also play important roles in cancer homeostasis, metastasis, resistance to therapy, and subsequent tumor recurrence [43]. Pancreatic CSCs are highly resistant to a majority of chemotherapeutic agents [44].

It is unknown whether silibinin affects pancreatic cancer stemness. The present study demonstrated that after exposure to silibinin, the expression levels of cancer stemness-related genes increase in human pancreatic cancer cells and other organ cancer cells, such as HepG2 (hepatocarcinoma cell line) and HCT116 (colon adenocarcinoma cell line); conversely, they decrease in human normal pancreatic ductal cells (hTERT-HPNE) and normal kidney cells (293T) (Figure 5). These results suggest that the effects of silibinin on pancreatic cancer cells and pancreatic normal ductal cells differ.

p53 is a tumor suppressor protein encoded by the Tp53 gene. p53 is an important cell-cycle inhibitor that prevents cancer in multicellular organisms. A mutation in the p53 protein cannot kill damaged cells. However, other healthy cells can break down such damaged cells. If a mutation of the p53 gene does not allow the p53 protein to function properly, cells with the damaged DNA will progress to cell division. These damaged cells can continue to divide. They will not be able to recognize the damaged DNA, resulting in more mutations. Such mutations cause cancer [45-49]. p53 protein overexpression is a common genetic alteration, and occurs very early in the development of pancreatic cancer [50-51]. The results of the present study indicate that silibinin-induced increases in stemnessrelated signals may be mediated by mutations in the $\mathrm{p} 53$ protein. In normal pancreatic ductal cells (hTERT-HPNE) that overexpress wild-type p53, silibinin increases the p53 protein levels. However, it decreases the p53 protein levels in p53-mutated cells such as MIA $\mathrm{PaCa}-2$ and PANC-1 cells that overexpress wild-type p53 (Figure 6). These results suggest that mutations in p53 may influence the effect of silibinin. However, the present study did not demonstrate that silibinin increases the expression of stemness-related genes, such as those of c-Jun, TWIST1, and Snail, in wild-type p53 pancreatic adenocarcinoma cells. Further studies are necessary to investigate the relationship between wild-type p53 pancreatic adenocarcinoma cells (such as SW1990) and silibinin.

Silibinin not only exerts anticancer effects by inhibiting AKTERK and JNK, but also increases the expression of cancer stemnessrelated genes in human pancreatic adenocarcinoma cells. However, silibinin does not have an adverse effect on pancreatic normal ductal cells.

In conclusion, pancreatic cancer cells susceptible to silibinin undergo cell death; on the other hand, if pancreatic cancer cells become resistant to silibinin and survive, it is possible that they will engage in activity similar to that of CSCs. These results suggest that when silibinin is used as a therapeutic agent for human pancreatic cancer, caution should be exercised.

\section{Funding}

Dr. Park was supported by a research grant from the Research institute of Medical Sciences, Chonnam National University (2015-CURIMS-DR003).

\section{References}

1. Mizrahi JD, Surana R, Valle JW, Shroff RT, Pancreatic cancer. Lancet. 2020; 395: 2008-2020.

2. Schizas D, Charalampakis N, Kole C, Economopoulou P, Koustas E, Gkotosis E, et al. Immunotherapy for pancreatic cancer; A 2020 update. Cancer Treat Rev. 2020; 86: 102016.

3. Zhu H, Wei M, Xu J, Hua J, Liang $\mathrm{C}$, Meng Q, et al. PARP inhibitors in pancreatic cancer: molecular mechanisms and clinical applications. Mol Cancer. 2020; 19: 49

4. Schneider G, Siveke JT, Eckel F, Schmid RM. Pancreatic cancer: basic and clinical aspects. Gastroenterology. 2005; 128: 1606-1625.

5. Camfield DA, J Sarris, M Berk. Nutraceuticals in the treatment of obsessive compulsive disorder (OCD): a review of mechanistic and clinical evidence. Prog Neuropsychopharmacol Biol Psychiatry. 2011; 35: 887-895.

6. Saller R, Brignoli R, Meizer J, Meier R. An updated systematic review with meta-analysis for the clinical evidence of silymarin. Forsch Komplementmed. 2008; 15: 9-20.

7. Al-Anati L, Essid E, Reinehr R, Petzinger E. Silibinin protects OTA-mediated TNF-alpha release from perfused rat livers and isolated rat Kupffer cells. Mol Nutr Food Res. 2009; 53: 460-466.

8. Federico A, Dallio M, Loquercio C. Silymarin/Silybin and Chronic Liver Disease: A Marriage of Many Years. Molecules. 2017; 22.

9. Deep, G and R Agarwal. Antimetastatic efficacy of silibinin: molecular mechanisms and therapeutic potential against cancer. Cancer Metastasis Rev. 2010; 29: 447-463.

10. Panattoni L, P Brown, J Windsor. Do market fees differ from relative value scale fees? Examining surgeon payments in New Zealand. J Health Serv Res Policy. 2011; 16: 203-210.

11. Chatran M, Pilehvar-Soltanahmadi Y, Dadashpour M, et al. Synergistic Antiproliferative Effects of Metformin and Silibinin Combination on T47D Breast Cancer Cells via hTERT and Cyclin D1 Inhibition. Drug Res (Stuttg). 2018.

12. Amawi H, Hussein NA, Ashby CR, et al. Bax/Tubulin/Epithelial-Mesenchymal Pathways Determine the Efficacy of Silybin Analog HM015k in Colorectal Cancer Cell Growth and Metastasis. Front Pharmacol. 2018; 9: 520.

13. Zhang $X$, Liu J, Zhang $P$, et al. Silibinin induces $G 1$ arrest, apoptosis and 
JNK/SAPK upregulation in SW1990 human pancreatic cancer cells. Oncol Lett. 2018; 15: 9868-9876.

14. Zhang Y, Ge Y, Ping X, Yu M, Lou D, Shi W. Synergistic apoptotic effects of silibinin in enhancing paclitaxel toxicity in human gastric cancer cell lines. Mol Med Rep. 2018; 18: 1835-1841.

15. Zhang X, Jiang J, Chen Z, Cao M. Silibinin inhibited autophagy and mitochondrial apoptosis in pancreatic carcinoma by activating JNK/SAPK signaling. Pathol Res Pract. 2019; 215: 152530.

16. Zhang $X$, Liu J, Zhang $P$, et al. Silibinin induces $G 1$ arrest, apoptosis and JNK/SAPK upregulation in SW1990 human pancreatic cancer cells. Oncol Lett. 2018; 15: 9868-9876.

17. Yang J, Sun Y, Xu F, et al. Silibinin ameliorates amylin-induced pancreatic $\beta$-cell apoptosis partly via upregulation of GLP-1R/PKA pathway. Mol Cell Biochem. 2019; 452: 83-94

18. Nambiar D, Prajapati $V$, Agarwal $R$, Singh RP. In vitro and in vivo anticance efficacy of silibinin against human pancreatic cancer BxPC-3 and PANC-1 cells. Cancer Lett. 2013; 334: 109-117.

19. O’Brien, CA, Pollett A, Gallinger S, Dick JE. A human colon cancer cell capable of initiating tumour growth in immunodeficient mice. Nature. 2007; 445: 106-110.

20. Scopelliti A, Cammareri P, Catalano V, Todaro M, Stassi G. Therapeutic implications of Cancer Initiating Cells. Expert Opin Biol Ther. 2009; 9: 10051016.

21. De Craene B, Berx G. Regulatory networks defining EMT during cance initiation and progression. Nat Rev Cancer. 2013; 13: 97-110.

22. Vogt PK. Fortuitous convergences: the beginnings of JUN. Nat Rev Cancer. 2002; 2: 465-469.

23. Lopez-Bergami P, Huang C, Goydos JS, et al. Rewired ERK-JNK signaling pathways in melanoma. Cancer Cell. 2007; 11: 447-460.

24. Wisdom R, Johnson RS, Moore C. C-Jun regulates cell cycle progression and apoptosis by distinct mechanisms. EMBO J. 1999; 18: 188-197.

25. Eferl R, Ricci R, Kenner L, et al. Liver tumor development. c-Jun antagonizes the proapoptotic activity of p53. Cell. 2003; 112: 181-192.

26. Zhang $\mathrm{Y}, \mathrm{Pu} \mathrm{X}$, Shi $\mathrm{M}$, et al. Critical role of $\mathrm{c}$-Jun overexpression in liver metastasis of human breast cancer xenograft model. BMC Cancer. 2007; 7: 145.

27. Bourgeois $P$, Stoetzel C, Bolcato-Bellemin AL, Mattei MG, Perrin-Schmitt $F$ The human $\mathrm{H}$-twist gene is located at $7 \mathrm{p} 21$ and encodes a $\mathrm{B}-\mathrm{HLH}$ protein that is $96 \%$ similar to its murine M-twist counterpart. Mamm Genome. 1996 7: $915-917$.

28. Dollfus H, Kumaramanickavel G, Biswas $P$, et al. Identification of a new TWIST mutation (7p21) with variable eyelid manifestations supports locus homogeneity of BPES at 3q22. J Med Genet. 2001; 38: 470-472.

29. Martin TA, Goyal A, Watkins G, Jiang WG. Expression of the transcription factors snail, slug, and twist and their clinical significance in human breast cancer. Ann Surg Oncol. 2005; 12: 488-496.

30. Puisieux A, Valsesia-Wittmann S, Ansieau S. A twist for survival and cancer progression. Br J Cancer. 2006; 94: 13-17.

31. Khan MA, Chen HC, Zhang D, Fu J. Twist: a molecular target in cancer therapeutics. Tumour Biol. 2013; 34: 2497-2506.

32. Roberts CM, Tran MA, Pitruzzello MC, et al. TWIST1 drives cisplatin resistance and cell survival in an ovarian cancer model, via upregulation of GAS6, L1CAM, and Akt signalling. Sci Rep. 2016; 6: 37652.
33. Paznekas WA1, Okajima K, Schertzer M, Wood S, Jabs EW. Genomic organization, expression, and chromosome location of the human SNAIL gene (SNAI1) and a related processed pseudogene (SNAI1P). Genomics. 1999; 62: 42-49.

34. Davidson NE1, Sukumar S. Of Snail, mice, and women. Cancer Cell. 2005; 8: $173-174$.

35. Ozaki T, Yu M, Yin D, et al. Impact of RUNX2 on drug-resistant human pancreatic cancer cells with p53 mutations. BMC Cancer. 2018; 18: 309.

36. Michal Sobecki, Karim Mrouj, Alain Camasses, et al. The cell proliferation antigen Ki-67 organises heterochromatin, eLife. 2016; e13722.

37. Shukla SK, Dasqupta A, Mehla K, et al. Silibinin-mediated metabolic reprogramming attenuates pancreatic cancer-induced cachexia and tumor growth. Oncotarget. 2015; 6: 41146-41161.

38. Feng W, Cai D, Zhang B, Lou G, Zou X. Combination of HDAC inhibitor TSA and silibinin induces cell cycle arrest and apoptosis by targeting survivin and cyclinB1/Cdk1 in pancreatic cancer cells. Biomed Pharmacother. 2015; 74: 257-264.

39. Nambiar D, Prajapati V, Agarwal R, Singh RP. In vitro and in vivo anticancer efficacy of silibinin against human pancreatic cancer BxPC-3 and PANC-1 cells. Cancer Lett. 2013; 334: 109-117.

40. Ge, Y, Zhang Y, Chen Y, et al. Silibinin causes apoptosis and cell cycle arrest in some human pancreatic cancer cells. Int J Mol Sci. 2011; 12: 4861-4871.

41. MJ Lukey, KS Greene, JW Erickson, KF Wilson, RA Cerione. The oncogenic transcription factor c-Jun regulates glutaminase expression and sensitizes cells to glutaminase-targeted therapy. 2016; 7: 11321.

42. Johnson $\mathrm{GL}, \mathrm{R}$ Lapadat. Mitogen-activated protein kinase pathways mediated by ERK, JNK, and p38 protein kinases. Science. 2002; 298: 1911-1912.

43. O'Brien CA, Pollett A, Gallinger S, Dick JE, A human colon cancer cell capable of initiating tumour growth in immunodeficient mice. Nature. 2007; 445: 106-110.

44. Scopelliti A, Cammareri P, Catalano V, Todaro M, Stassi G. Therapeutic implications of Cancer Initiating Cells. Expert Opin Biol Ther. 2009; 9: 10051016.

45. Ling $X$, Wu W, Fan $C$, et al. An ABCG2 non-substrate anticancer agent FL118 targets drug-resistant cancer stem-like cells and overcomes treatment resistance of human pancreatic cancer. J Exp Clin Cancer Res. 2018; 37: 240.

46. Johnson GL, R Lapadat, Mitogen-activated protein kinase pathways mediated by ERK, JNK, and p38 protein kinases. Science. 2002; 298: 1911-1912.

47. Mraz M, Malinova K, Kotaskova J, Pospisilova S, et al. miR-34a, miR-29c and miR-17-5p are downregulated in CLL patients with TP53 abnormalities. Leukemia. 2009; 23: 1159.

48. Dolezalova D, Mraz M, Barta T, et al. MicroRNAs regulate p21(Waf1/Cip1) protein expression and the DNA damage response in human embryonic stem cells. Stem Cells. 2012; 30: 1362-1372.

49. Bates S, Phillips AC, Clark PA, et al. p14ARF links the tumour suppressors RB and p53. Nature. 1998; 395: 124-125.

50. Hu W, Feng Z, Teresky AK, Levine AJ, p53 regulates maternal reproduction through LIF. Nature. 2007; 450: 721-724.

51. Boschman CR, Stryker S, Reddy JK, Rao MS, Expression of p53 protein in precursor lesions and adenocarcinoma of human pancreas. Am J Pathol. 1994; 145: 1291-1295. 